\title{
LEVANTAMENTO DO POTENCIAL DE ARBORIZAÇÃO E PROPOSTA PARA TRÊS BAIRROS NO MUNICÍPIO DE PIRACICABA/SP, BRASIL.
}

\author{
Demóstenes Ferreira Silva Filho ${ }^{1}$, Ana Maria Meira ${ }^{2}$, Carlos Roberto Sette $\mathrm{Jr}^{2}{ }^{2}$, Eduardo \\ Roberto Alexandrino ${ }^{2}$, Cláudia de Lima Nogueira ${ }^{2}$, Eliane Guaraldo ${ }^{3}$, Francielle Olivatto ${ }^{2}$, \\ Francisco Martins de Almeida Rollo ${ }^{2}$, Julieth Parra², Matheus Peres Chagas ${ }^{2}$, Milene \\ Bianchi $^{2}$, Murilo Vieira Gabriel${ }^{2}$, Rose M. G. S. Celidonio ${ }^{2}$, Sandra Monteiro Borges \\ Florsheim², Talita Jeanne da Costa ${ }^{2}$
}

(recebido em 15.04.2008 e aceito para publicação em 18.12.2008)

\section{RESUMO}

A maioria dos municípios do Brasil apresenta grande déficit de indivíduos arbóreos urbanos, o que acarreta problemas ambientais diversos. O objetivo do presente trabalho foi avaliar o potencial e propor desenhos alternativos de arborização urbana para três bairros com situação de cobertura arbórea crítica na cidade de Piracicaba/SP. Cada bairro foi avaliado pelo processamento, com uso do software TNT Mips 7.2, de imagens aéreas obtidas por videografia multiespectral e pelo reconhecimento em campo. Com base nas informações geradas e considerando a baixa ocorrência de indivíduos arbóreos, foram selecionadas, de forma sistemática, 10 quadras de cada bairro, para a realização das propostas de intervenção. As alternativas de desenho propostas, para os três bairros, foram arborização de: (i) calçadas, sempre que as condições de fiação, rede de esgoto e entrada de garagem permitissem, (ii) canteiros centrais em ruas com leito carroçável largo, situação comumente encontrada nos bairros, (iii) rotatórias e (iv) praças e áreas verdes. Os bairros estudados apresentaram condições de intervenção paisagística e implementação de arborização (novas árvores), o que proporcionaria uma melhoria das condições ambientais futuras, com a previsão de um efetivo aumento da cobertura arbórea destes bairros e, conseqüentemente, do bem estar de sua comunidade.

Palavras-chave: silvicultura urbana, potencial de arborização, propostas de arborização, Piracicaba (SP).

\footnotetext{
${ }^{1}$ Engenheiro Agrônomo - Professor Doutor ESALQ/USP - Laboratório de Silvicultura Urbana / Centro de métodos Quantitativos - Piracicaba/SP, Endereço: Av.: Pádua Dias, 11, CP 9, Piracicaba - SP, 13418-900, <dfsilva@esalq.usp.br><http://lmq.esalq.usp.br/wiki/doku.php>;

${ }^{2}$ Programa de Pós Graduação em Recursos Florestais e Ecologia Aplicada ESALQ/USP, alunos da disciplina Silvicultura Urbana;

${ }^{3}$ Arquiteta e Urbanista - FAU/USP.
} 


\title{
URBAN FOREST POTENTIAL SURVEY AND PROPOSAL FOR THREE NEIGHBORHOODS IN THE CITY OF PIRACICABA/SP, BRAZIL.
}

\begin{abstract}
The majority of the Brazilian cities present a great deficit of urban trees causing a lot of environmental problems. The objective of the present work was to evaluate the potential and propose alternative urban design of new urban forestry for three neighborhoods with critical arboreal covering situation in Piracicaba, São Paulo State, Brazil. Each neighborhood was evaluated by the processing, using the software TNT Mips 7.2, of aerial images obtained by multispectral videography and for the recognition in field. Based in the generated information, and considering the low occurrence of arboreal individuals, 10 blocks of each neighborhood were select in a systematic way, for the accomplishment of the intervention proposals. The drawing alternatives proposed, for the three neighborhoods, were the urban forestry of: (i) sidewalks, whenever the spinning conditions, sewerage system and garage entrance allow, (ii) central stonemasons in large streets, situation commonly found in the neighborhoods, (iii) rotating, and (iv) squares and green areas. The studied neighborhoods present conditions of landscaping intervention and implementation of new trees, what would provide an improvement of the future environmental conditions with the increase of an effective canopy covering of these neighborhoods and, consequently, of the welfare of its community
\end{abstract}

Key-words: urban forestry, urban forest increment potential, urban forest proposals, Piracicaba (SP). 


\section{INTRODUÇÃO}

A ocupação humana dos ambientes terrestres é algo incessante; com isso, a urbanização vem crescendo em ritmos constantes (Vitousek et al., 1997) e de forma irreversível. Novos lotes e bairros são criados em várias cidades em expansão, causando drásticas mudanças nos ambientes originais circundantes.

A urbanização é uma das maiores causadoras de alterações permanentes nos ambientes naturais. Os municípios mantêm uma baixa taxa de similaridade com a paisagem original, tornando o ambiente dificilmente recuperável ao que era antes (Marzluff e Ewing, 2001).

As crescentes atividades humanas geraram intensas transformações na superfície terrestre (Smith et. al 1996) e, em conseqüência, as cidades também ajudam a acelerar tais mudanças. Ichinose et al. (1999) e Monteiro e Mendonça (2003) explanaram sobre as modificações micro e macro climáticas causadas pelos centros urbanos. Do mesmo modo, problemas como concentrações de poluentes são observados (Vasconcelos et al., 2007), acarretando problemas de saúde entre os humanos (Peng et al., 2002, Jacquemin et al., 2007).

Como forma de enfrentar este constante crescimento, o complexo ecossistema urbano vem sendo intensamente monitorado, em virtude de seu impacto potencial na biodiversidade (Wackernagel e Rees 1996), em parte pelo interesse de criar e manter cidades e regiões que possam ser ecologicamente sustentáveis (Rees, 1997, Nilon et al., 1999). Entretanto, dentro deste cenário de expansão, ainda é comum a falta de um planejamento adequado para conduzir o processo de urbanização de uma forma menos impactante, problema observado em vários paises em desenvolvimento (Timár, 1992).

Alguns aspectos, como a criação de parques públicos, florestas urbanas e uma eficiente arborização pública podem minimizar os efeitos destas transformações drásticas no ambiente (Grey e Deneke, 1978, Jim e Chen, 2003).

O conjunto de árvores urbanas, também denominado floresta urbana (Moll, 1988), promove diversos benefícios sociais e ambientais às cidades. A arborização pode atuar na redução dos efeitos de ilhas de calor (Shashua-bar e Hoffman, 2003), pode diminuir a velocidade dos ventos (Grey e Deneke, 1978), permitir maior permeabilidade do solo e reduzir o escorrimento superficial, minimizando assim o risco de enxurradas (Paiva e Gonçalves, 2002). São favorecidas características climáticas e ambientais ótimas, evitando as áreas escassas de flora e fauna e o desconforto ambiental (Silva e Magalhães, 1993), além de poderem fornecer locais mais atrativos para o lazer, para as atividades físicas e promover melhor qualidade de vida (More et al., 1988, Paiva e Gonçalves, 2002). A presença de maciços verdes garante a ligação entre as áreas verdes dentro das cidades, 
bem como destas com as suas paisagens naturais circunvizinhas, comportando-se como greenways (Ahern, 2002; Bryant, 2006; Frischenbruder e Pellegrino, 2006).

No entanto, a preocupação em realizar um planejamento urbano que vise a destinar um efetivo espaço verde, ora objetivando a qualidade de vida e o papel ecológico, ora proporcionando a valorização monetária do local, ainda é pouco explorada, sendo uma causa relativamente recente (Ahern, 2002). Além disso, um dos grandes desafios de se implantarem novas árvores no meio urbano é conciliar sua presença com as diversas instalações urbanas, como redes hidráulicas, elétricas, telefônicas e sanitárias (Soares, 1998), que, muitas vezes, são alocadas primeiramente, sem prever reserva de espaço para a arborização.

Logo, a falta de planejamento público, ao permitir a ocupação do espaço urbano sem a reserva adequada de espaços de amenização perfaz um cenário inadequado e difícil de reverter quanto ao destino de locais para serem plantadas novas árvores em um bairro.

Dentre diversos municípios que enfrentam tal problema, é apresentado o município de Piracicaba, Estado de São Paulo. De acordo com Rollo et al. (2007), nesta cidade, são encontrados bairros insuficientemente arborizados, em proporção à sua importância econômica e ao seu espaço geográfico.

O presente estudo analisou três zonas diferentes de Piracicaba/SP, que apresentam um cenário de escassez de cobertura arbórea, com o objetivo de avaliar possíveis locais propícios ao plantio de espécies arbóreas em vias públicas, além de sugerir alternativas que visem à facilitação do plantio, atentou-se também para as características microclimáticas de cada bairro e a influência do aumento de cobertura vegetal em tais características.

\section{MATERIAIS E MÉTODOS}

\section{Área de estudo}

O estudo foi realizado no município de Piracicaba, localizado no interior do Estado de

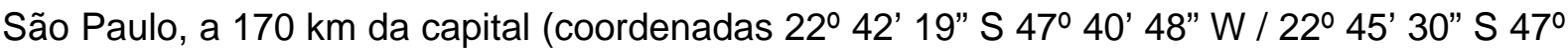
37' 38" W). Seu perímetro urbano ocupa, aproximadamente, 7.851 ha (Barreto et al. 2006), sendo este atravessado pelo rio Piracicaba. De acordo com o senso do Instituto Brasileiro de Geografia e Estatística (2007), a cidade possui população estimada de 357.108 habitantes.

Três bairros, predominantemente residenciais, foram amostrados neste estudo: Piracicamirim, Nova América e Jardim Monumento. Respectivamente, possuem aproximadamente 97,6, 91 e 55,1 ha de área. Os dois primeiros estão localizados na região sudeste da cidade, enquanto o último localiza-se na região noroeste (Figura 1). Todos possuem uma densidade populacional de 50 a 100 hab/ha, o que os enquadram na mesma 
faixa de densidade da área central (Instituto de Pesquisa e Planejamento de Piracicaba, 2007). Tais bairros foram escolhidos por apresentarem baixa porcentagem de cobertura vegetal em relação a outros bairros do município, como apresentado em Rollo et. al. (2007) para os bairros Piracicamirim e Jardim Monumento, e como constatado pelos autores para o bairro Nova América (informação pessoal).

Os bairros em estudo englobam cenários bastante distintos, mesclando loteamentos novos com mais antigos, terrenos vazios, muitas casas de meio lote e com garagem ocupando toda a frente do mesmo. O histórico de urbanização destes bairros demonstra que o mais velho é o Nova América, com início da ocupação ainda na década de 1940, seguido do Piracicamirim (inicio na partir da década de 1950) e do Jardim Monumento (início na década de 1970) (Instituto de Pesquisa e Planejamento de Piracicaba, 2007).

No Piracicamirim, um ribeirão que possui o mesmo nome do bairro atravessa seu limite, estando toda a ocupação do bairro localizada em sua margem direita.

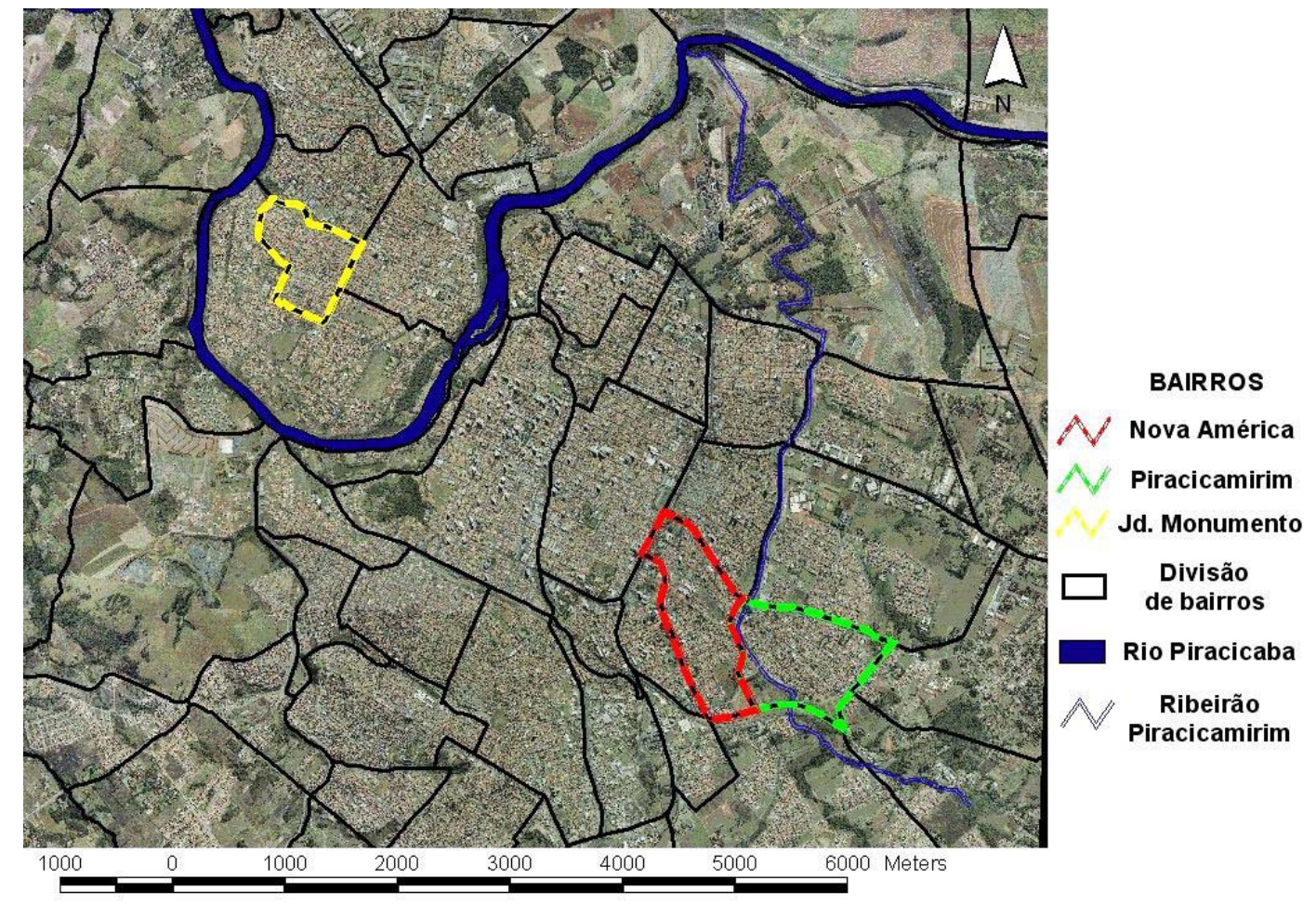

Figura 1. Fotografia aérea de Piracicaba/SP. Em detalhe, os três bairros amostrados. Fotografia de: BASE Aerofotogrametria e Projetos S.A, 2000.

\section{Métodos de amostragem e propostas sugeridas}

Para o reconhecimento dos bairros amostrados e a avaliação dos locais públicos propícios a novos planos de arborização, foram formadas três equipes de pesquisadores, e cada uma ficou responsável por um bairro. Cada bairro foi avaliado com auxílio de imagens 
aéreas dos locais, obtidas por videografia aérea multiespectral no ano de 2005 (foram obtidas imagens aéreas de toda a área urbana do município), processadas no software TNT Mips 7.2, e o procedimento seguido é descrito em Rollo et al. (2007). Além disso, tais dados foram combinados com as informações obtidas no reconhecimento de trechos das ruas amostradas e de registros fotográficos simples dos locais, na escala do pedestre. Estas imagens foram justapostas com o auxílio do software Adobe Photoshop CS 8, para facilitar a visualização de toda extensão das ruas. Tal procedimento permitiu estudar a dinâmica existente entre arborização, garagens e mobiliários urbanos nas ruas amostradas (Figura 2).

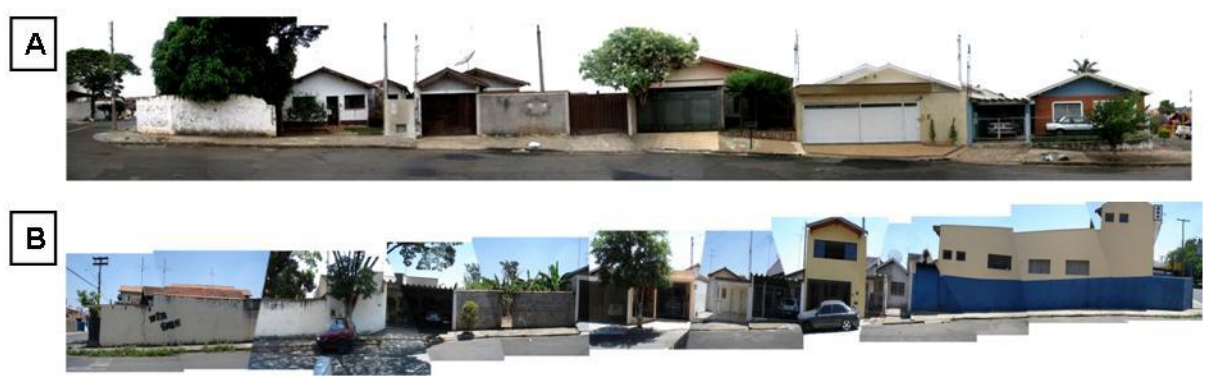

Figura 2. (A) Aspecto geral da face 1 da rua Machado de Assis, Bairro Nova América, (B) Aspecto geral da face 1 da rua Jaccob Wagner, Bairro Piracicamirim. Piracicaba, SP, 2007.

Como existem singularidades nos bairros analisados, optou-se por não padronizar a aplicação de procedimentos e ferramentas de avaliação, pois tal padronização não permitiria aprofundar a análise nos pontos críticos observados. Os procedimentos e ferramentas de avaliação escolhidos foram os que melhor auxiliavam na compreensão da problemática e das características locais do bairro.

Para a apresentação da proposta de arborização, foram utilizados os recursos do software Autocad 2007.

Abaixo, seguem as particularidades de cada bairro.

\section{Piracicamirim}

Somando aos dados de videografia, as ruas do bairro foram reconhecidas percorrendo toda sua extensão, atentando-se para localização dos postes e fios elétricos, medidas de largura de calçadas e do leito carroçável. Também foi consultada a planta cartográfica digitalizada ano base 2002, cedida pelo Instituto de Pesquisa e Planejamento de Piracicaba (IPPLAP) sobre a localização da rede de abastecimento de água e de captação de esgoto. 
Logo após a etapa de reconhecimento, foram escolhidas 10 faces de quarteirões consideradas como representativas do bairro por apresentarem locais propícios a receber novas árvores, onde foram analisados os fatores condicionantes à arborização.

\section{Jardim Monumento}

Para reconhecimento e identificação dos possíveis locais para arborização, foram realizadas 10 amostragens aleatórias de ruas a partir de imagens aéreas multiespectrais de alta resolução, confirmadas por visita ao local. As variáveis observadas e medidas foram: largura do calçamento, largura do leito carroçável, altura da guia, fiação, rede de esgoto presente junto à calçada, ocorrência de arborização, bem como as condições de desenho e padrões urbanísticos e de ocupação dos lotes.

Para a localização da rede de abastecimento de água e de captação de esgoto deste bairro também foi utilizada a mesma base cartográfica cedida pelo IPPLAP.

\section{Nova América}

Com os dados obtidos de cobertura arbórea do bairro, foi realizada, posteriormente, uma estratificação em (i) áreas críticas (baixa a nula densidade de cobertura vegetal) e (ii) áreas não críticas (média a alta densidade de cobertura vegetal). Nas áreas consideradas críticas, foram selecionadas, em amostragem sistemática, 10 quadras, com o intuito de diagnosticar "in loco" a situação dessas quadras, e, assim, propor alternativas para a melhoria da arborização do bairro.

As principais variáveis levantadas durante o reconhecimento das quadras foram: largura do leito carroçável e da calçada (2 faces), presença de fiação elétrica (simples ou compacta), tamanho dos lotes, e quantidade, espécie e porte dos indivíduos arbóreos presentes no bairro.

\section{Diagnóstico do micro clima dos bairros}

Para todos os bairros amostrados, foram feitos os cálculos de estimativa de grau-hora calor (GHC). De acordo com Roriz (2001), consideram-se graus-hora a quantidade de graus que ultrapassa a temperatura de neutralidade térmica ANSI/ASHRAE (2004), também conhecida com a temperatura de conforto. Quanto menor a GHC encontrada num bairro, menor será a necessidade de graus que devem ser perdidos para atingir esta temperatura de neutralidade. Sendo assim, menor será a necessidade de haver resfriamento artificial no bairro. Para um diagnóstico do micro clima dos bairros estudados, partiu-se do pressuposto de que a quantidade de grau-hora calor correlaciona-se negativamente com a quantidade de 
cobertura arbórea de um determinado local, assim como salientado em Velasco (2007). Nesta literatura é apresentada um modelo matemático da qual pode ser utilizada para o cálculo de GHC de um local, durante o mês de março, a partir da quantidade de cobertura arbórea encontrada. Logo, para cada um dos três bairros estudados, foram calculados o GHC encontrado atualmente, e para um cenário futuro, caso as propostas de arborização sejam efetivadas. Para isso, utilizaram-se os dados de porcentagem de cobertura arbórea extraídos de videografia aérea. Foi Seguido o seguinte modelo:

\section{$\mathrm{GHC}=3.86519+8.74161 * \operatorname{Exp}(-\mathrm{V} / 8.57406)$,}

Fonte: Velasco (2007)

Onde $\mathrm{V}$ é a porcentagem de cobertura arbórea encontrada em cada bairro.

Para estimar o ganho de cobertura arbórea nos bairros, foi adotado o valor de 15 metros de diâmetro de copa, ou seja, $176.63 \mathrm{~m}^{2}$ de área, para cada nova árvore plantada nos locais identificados como propícios a recebê-las.

\section{RESULTADOS E DISCUSSÃO}

As análises das imagens de videografia aérea por meio da classificação automática supervisionada revelaram uma baixa porcentagem de cobertura arbórea nos bairros amostrados (Tabela 1), quando comparados com dados de demais bairros. Segundo Rollo et. al. (2007b) alguns bairros da cidade ultrapassam 15\% de presença arbórea dentro de seus limites territoriais, como é o caso do bairro Clube de Campo (26,09\%), e Nova Piracicaba (18,15\%).

Tabela 1. Porcentagem de cobertura arbórea encontrada em cada bairro atualmente

\begin{tabular}{c|cc}
\hline Bairro & Área (ha) (valor aproximado) & Cobertura arbórea atual (\%) \\
\hline Piracicamirim & 97,6 & 6,95 \\
\hline Jd. Monumento & 55,1 & 7,14 \\
\hline Nova América & 91 & 7,92 \\
\hline
\end{tabular}

O reconhecimento das ruas dos bairros retornou diferentes resultados de comprimentos de ruas e calçadas, como é apresentado nas tabelas subseqüentes.

\section{Piracicamirim}

As variáveis coletadas no reconhecimento do bairro são apresentadas na Tabela 2. 
Tabela 2. Parâmetros levantados nas quadras amostradas no bairro Piracicamirim

\begin{tabular}{clccccc}
\hline Quadra & \multicolumn{1}{c}{ Rua } & Leito carroçável $(\mathbf{m})$ & Sentido & Face & Calçada $(\mathbf{m})$ & Fiação \\
\hline 1 & Cinco & 8,9 & simples & 1.00 & 2,6 & presente \\
\hline 2 & Território do Acre & 9,0 & simples & 1.00 & 2,6 & ausente \\
\hline 3 & Jacob Wagner & 8 & duplo & 1.00 & 1,6 & ausente \\
\hline 4 & Av. Dois Córregos & 2 pistas com canteiro central & duplo & 1.00 & 2,5 & ausente \\
\hline 5 & Frei Tomé de Jesus & rua de terra & duplo & 1.00 & sem calçada & ausente \\
\hline 6 & Uruguai & 7,5 & simples & 1.00 & 1,5 & ausente \\
\hline 7 & Fernando de Noronha & 7,2 & duplo & 1.00 & 1,9 & ausente \\
\hline 8 & $\begin{array}{l}\text { Nelson Camponês do Brasil } \\
\text { (trecho 1) }\end{array}$ & 7,5 & duplo & 1.00 & 2,2 & ausente \\
\hline 9 & $\begin{array}{l}\text { Nelson Camponês do Brasil } \\
\text { (trecho 2) }\end{array}$ & 8 & duplo & 1.00 & 2,6 & ausente \\
\hline 10 & Rio Grande do Norte & 9 & duplo & 1.00 & 2,2 & ausente \\
\hline MÉDIA & & $\mathbf{8 , 3 3}$ & &
\end{tabular}

De acordo com os dados obtidos na Tabela 2, foram elaboradas estratégias de arborização para todas as faces amostradas neste trabalho. Entretanto, no presente estudo são apresentadas duas situações consideradas de maior importância, pelo seu impacto positivo na paisagem local. Buscou-se considerar os aspectos macros da paisagem, com a criação de dois eixos estruturadores que possibilitarão a concepção de corredores verdes; a preocupação em elaborar propostas factíveis e de baixo custo; a preocupação com a mobilidade, segurança do pedestre e qualidade de vida à população.

As propostas elaboradas (Figura 3) estão descritas, detalhadamente, a seguir.

\section{Proposta 1}

Rua Nelson Camponês do Brasil: esta proposta considera as ruas com leito carroçável de $8,00 \mathrm{~m}$, passeio público com 2,60m e lotes com testada de 5,00m a 10,00m. Pela considerável largura do passeio público, o plantio de árvores poderá ser efetuado na calçada, criando, sempre que possível, uma faixa verde para favorecer a permeabilização do solo. A largura do leito carroçável não será alterada. Para esta proposta, espécies como Tipuana (Tipuana tipu (Benth.) O. Kuntze), Chapéu de Sol (Terminalia catappa L.), Magnólia-amarela (Michelia champaca L.), e Ipê-roxo (Tabebuia heptaphylla (Vell.) Tol.) seriam algumas das mais indicadas, devido a sua boa capacidade de obtenção de copa. 


\section{Proposta 2}

Rua Uruguai: esta proposta considera as ruas com leito carroçável de 7,60m, passeio público com 1,60m e lotes com testada de 5,00m a 6,00m. Buscou-se melhorar a arborização do bairro sem entrar em conflito com o passeio do pedestre; para isto, o plantio de árvores ocorrerão a $10 \mathrm{~cm}$ da guia da calçada (possibilitando o escoamento da água pluvial), com canteiros de $1,00 \times 1,00 \mathrm{~m}$, alternados conforme a existência das garagens. $O$ leito carroçável ficará com $6,60 \mathrm{~m}$ de largura (adequado para vias locais). Nesta proposta específica, dentro da discussão da criação dos eixos estruturadores, a proposta contempla a implantação de uma ciclovia, conferindo segurança aos ciclistas e fortalecendo um transporte de baixo impacto ambiental.

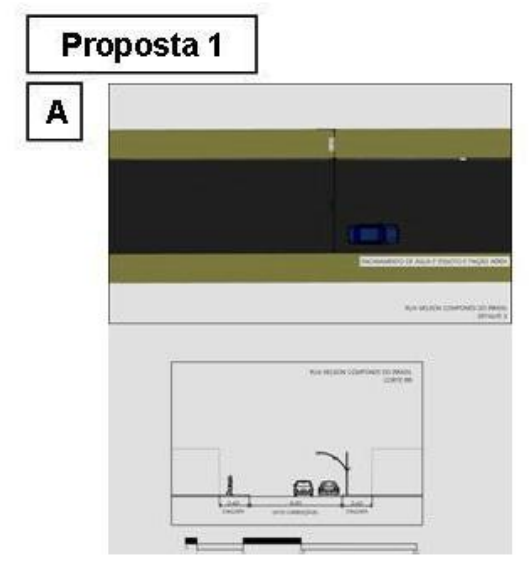

Proposta 2

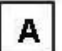

A
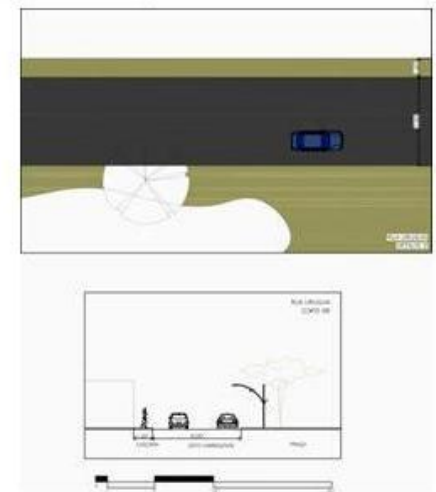

B

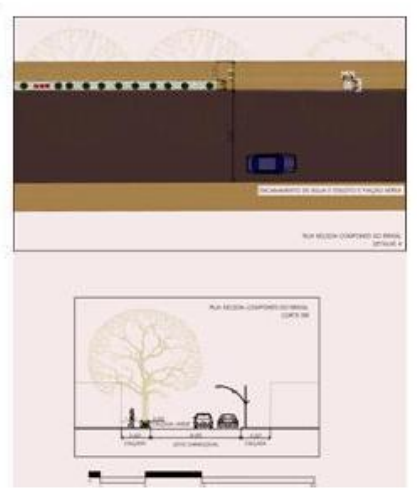

B

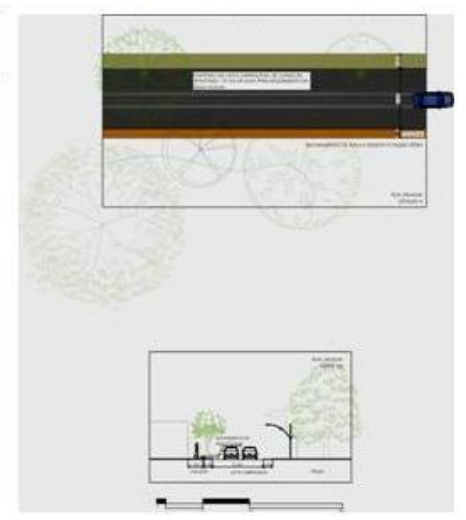

Figura 3. Propostas de desenhos para modificação do espaço físico de duas ruas amostradas do bairro Piracicamirim. Para cada proposta, são apresentadas a situação atual (A) e a situação proposta (B).

\section{Jardim Monumento}

Um resumo das variáveis obtidas durante o reconhecimento das quadras previamente selecionadas encontra-se na Tabela 3. 
Tabela 3. Parâmetros levantados nas quadras amostradas do bairro Jardim Monumento.

\begin{tabular}{|c|c|c|c|c|c|c|c|}
\hline Quadra & Rua & Face & $\begin{array}{c}\text { Guia } \\
\text { (m) }\end{array}$ & $\begin{array}{c}\text { Calçada } \\
(\mathbf{m})\end{array}$ & $\begin{array}{c}\text { Total } \\
(\mathbf{m})\end{array}$ & $\begin{array}{c}\text { Leito carroçável } \\
\text { (m) }\end{array}$ & Fiação \\
\hline \multirow{2}{*}{1} & \multirow{2}{*}{ Armando Bergamin } & 1 & 1,90 & 1,90 & 2,00 & \multirow{2}{*}{10,20} & \multirow{2}{*}{ em um lado apenas } \\
\hline & & 2 & 2,00 & 2,00 & 2,15 & & \\
\hline \multirow{2}{*}{2} & \multirow{2}{*}{ Armando Bergamin } & 1 & 1,90 & 1,90 & 2,00 & \multirow{2}{*}{10,20} & \multirow{2}{*}{ em um lado apenas } \\
\hline & & 2 & 2,00 & 2,00 & 2,15 & & \\
\hline \multirow{2}{*}{3} & \multirow{2}{*}{ Tenente Tomaz Nunes } & 1 & 1,85 & 1,85 & 1,95 & \multirow{2}{*}{10,00} & \multirow{2}{*}{ em um lado apenas } \\
\hline & & 2 & 1,80 & 1,80 & 1,90 & & \\
\hline \multirow{2}{*}{4} & \multirow{2}{*}{ Tenente Tomaz Nunes } & 1 & 1,90 & 1,90 & 2,00 & \multirow{2}{*}{10,00} & \multirow{2}{*}{ em um lado apenas } \\
\hline & & 2 & 1,85 & 1,85 & 1,95 & & \\
\hline \multirow{2}{*}{5} & \multirow{2}{*}{ Luiz Abrahão } & 1 & 1,90 & 1,90 & 2,03 & \multirow{2}{*}{9,00} & \multirow{2}{*}{ em ambos os lados } \\
\hline & & 2 & 2,35 & 2,35 & 2,50 & & \\
\hline \multirow{2}{*}{6} & \multirow{2}{*}{ Atahualpa Vaz de Mello } & 1 & 1,85 & 1,85 & 1,95 & \multirow{2}{*}{8,10} & \multirow{2}{*}{ em um lado apenas } \\
\hline & & 2 & 1,90 & 1,90 & 2,00 & & \\
\hline \multirow{2}{*}{7} & \multirow{2}{*}{ Barão de Serra Negra } & 1 & 2,90 & 2,90 & 3,00 & \multirow{2}{*}{10,10} & \multirow{2}{*}{ em um lado apenas } \\
\hline & & 2 & 3,90 & 3,90 & 3,90 & & \\
\hline \multirow{2}{*}{8} & \multirow{2}{*}{ Rafael Aloisi } & 1 & 2,30 & 2,30 & 2,45 & \multirow{2}{*}{9,00} & \multirow{2}{*}{ em um lado apenas } \\
\hline & & 2 & 2,40 & 2,40 & 2,50 & & \\
\hline \multirow{2}{*}{9} & \multirow{2}{*}{ Pedro Sacone } & 1 & 2,30 & 2,30 & 2,45 & POQ & m \\
\hline & & 2 & 2,40 & 2,40 & 2,50 & 9,00 & em um lado apenas \\
\hline 10 & Fornando Pallo 1 ara & 1 & 2,40 & 2,40 & 2,50 & 875 & Im um lodo anonoc \\
\hline 10 & Fernanuo Bello Lara & 2 & 2,40 & 2,40 & 2,50 & 8,15 & em um rado apenas \\
\hline MÉDIA & * & * & 2,21 & 2,2 & 2,32 & 9,4 & * \\
\hline
\end{tabular}

Diante dos dados mensurados e do reconhecimento visual das condições das quadras, foram elaboradas 3 propostas que visam ao aumento da área coberta por indivíduos arbóreos, melhorando assim as condições climáticas e o bem estar dos moradores do bairro.

\section{Proposta 1: Situações pontuais - arborização nas calçadas.}

Para formulação desta proposta, realizou-se uma análise pontual das calçadas ausentes de interferências como tubulações subterrâneas, equipamentos urbanos, fachadas residenciais, entrada de garagens, etc. Para as calçadas junto à testada lateral dos lotes, recomenda-se a arborização local e a colocação de canteiros lineares (Figura 4A). Para as calçadas frontais dos lotes, recomenda-se a arborização, quando possível, e também a instalação de canteiros lineares (Figura 4B).
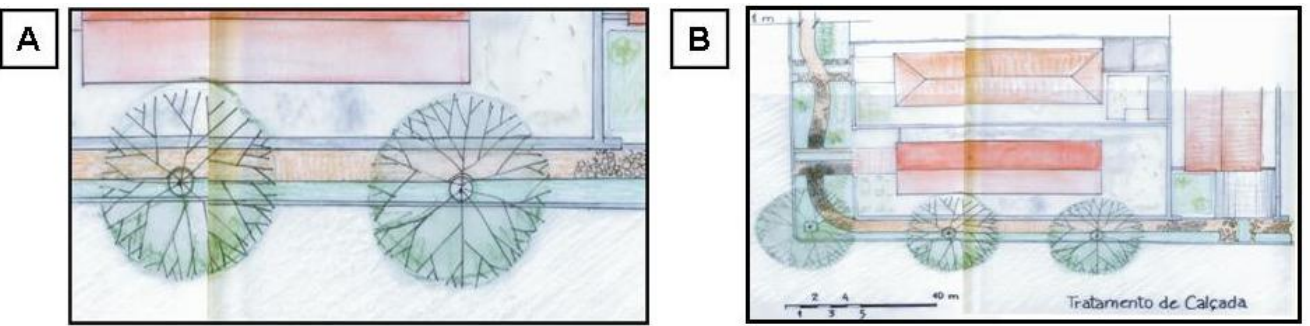

Figura 4. (A) Arborização em canteiros lineares na testada lateral das casas, (B) canteiros lineares na testada frontal das casas. 
Também se pretende, com esta proposta, a substituição de fiação convencional pela compacta (Tabela 4), favorecendo, assim, o plantio de indivíduos arbóreos de grande porte.

Tabela 4. Custo estimado para substituição da fiação elétrica tradicional para rede compacta.

\begin{tabular}{ll}
\hline ITEM & QUANTIFICAÇÃO \\
\hline Metragem de fio necessária $(\mathrm{km})$ & 11,384 \\
\hline Custo $(\mathrm{R} \$ / \mathrm{km})$ & $35.000,00$ \\
\hline Custo total estimado $(\mathrm{R} \$)$ & $398.440,00$ \\
\hline
\end{tabular}

Esta proposta pode ser indicada para todo o bairro, especialmente para a rua Atahualpa Vaz de Melo, por possuir a menor largura de leito carroçável (Figura 5).

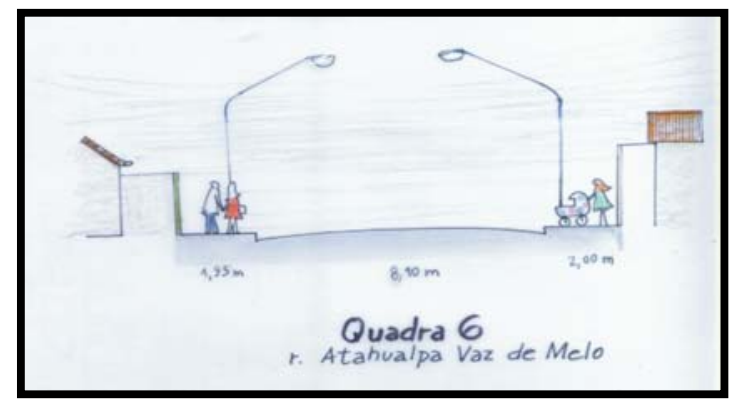

Figura 5. Dimensões das calçadas e leito carroçável da Rua Atahualpa Vaz de Melo.

A área atual arborizada do bairro corresponde a aproximadamente $39.372,00 \mathrm{~m}^{2}$, equivalente a 7,14\% da área total do bairro. Com a aplicação desta proposta, a área adicional disponível para arborização convencional (nas calçadas) passaria para, aproximadamente, $68.709,07 \mathrm{~m}^{2}$, aumentando a cobertura arbórea do bairro para 12,46\% de sua área total (em torno de 389 árvores).

\section{Proposta 2: Arborização de canteiros centrais e rotatórias.}

Esta proposta baseia-se na possibilidade de implantação de canteiros centrais em ruas mais largas (Figuras 6A e 6B), maiores que $9 \mathrm{~m}$ de largura, de sentido único ou duplo, também havendo a possibilidade de criação e arborização de rotatórias em seus cruzamentos (Figura 7). 
Neste caso, as espécies plantadas poderão ser de grande porte, resultando em uma maior área sombreada, sendo o espaçamento de plantio adotado, de 15 metros entre os indivíduos arbóreos. Nos intervalos, pode-se adotar, como alternativa, o plantio de espécies forrageiras.
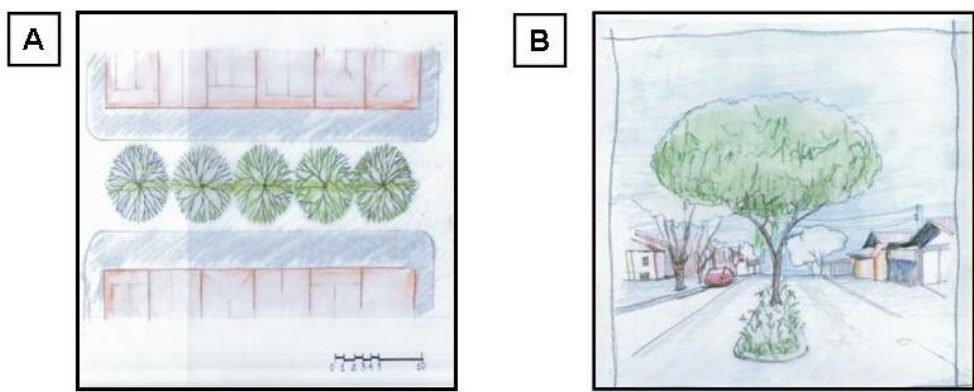

Figura 6. (A) Vista superior do canteiro central, (B) vista frontal do canteiro central.

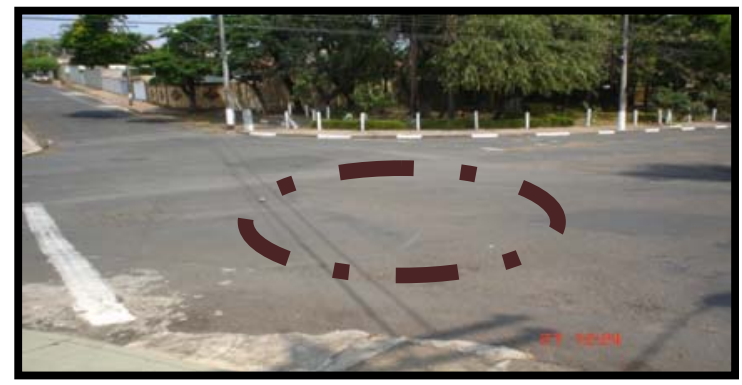

Figura 7. Cruzamento com possibilidade de criação de rotatória arborizada.

Com a proposta 2, a área adicional disponível para arborização é de, aproximadamente, $13.698,62 \mathrm{~m}^{2}$, equivalente a 78 árvores, correspondendo a 2,48\% da área total do bairro.

\section{Proposta 3: Arborização e planejamento de praças e áreas verdes.}

Esta proposta visa a arborizar espaços não pavimentados do bairro e sem cobertura arbórea, como praças e áreas verdes (Figura 8). Em função da declividade do local, o espaço poderá ser melhor aproveitado pelos moradores do bairro, desde que receba um projeto paisagístico. 


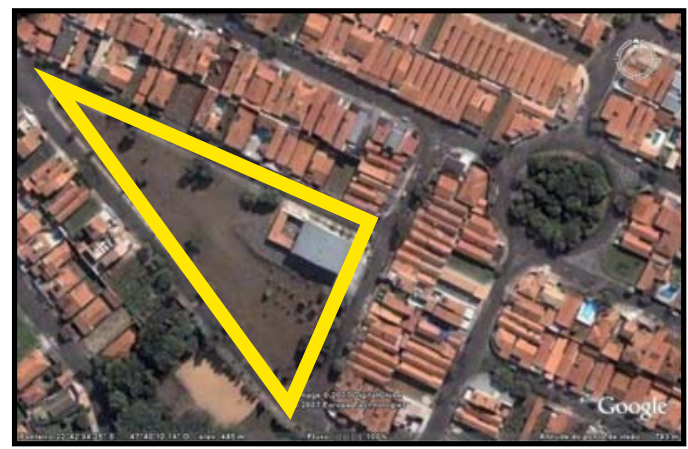

Figura 8. Área verde não arborizada no bairro.

Com esta proposta, é possível arborizar $7.500 \mathrm{~m}^{2}$, o que representa a implantação de 42 árvores, que equivalem a 1,36\% da área total do bairro.

\section{Nova América}

As principais variáveis levantadas durante o reconhecimento das quadras selecionadas estão apresentadas na Tabela 5.

Tabela 5. Parâmetros levantados nas quadras amostradas no bairro Nova América.

\begin{tabular}{|c|c|c|c|c|c|c|c|}
\hline Quadra & Rua & Sentido & Face & Calçada (m) & Leito carroçável (m) & $\mathrm{N}^{\circ}$ de árvores & Fiação \\
\hline \multirow{2}{*}{1} & \multirow{2}{*}{ Capitão Mor Goes de Aranha } & \multirow{2}{*}{ duplo } & 1 & 1.90 & \multirow{2}{*}{7.80} & 1 & \multirow{2}{*}{ em um lado apenas } \\
\hline & & & 2 & 3.40 & & 1 & \\
\hline \multirow{2}{*}{2} & \multirow{2}{*}{ Angelino Prezzoto } & \multirow{2}{*}{ duplo } & 1 & 2.60 & \multirow{2}{*}{8.00} & 0 & \multirow{2}{*}{ em um lado apenas } \\
\hline & & & 2 & 2.60 & & 1 & \\
\hline \multirow{2}{*}{3} & \multirow{2}{*}{ Machado de Assis } & \multirow{2}{*}{ duplo } & 1 & 2.50 & \multirow{2}{*}{8.90} & 0 & \multirow{2}{*}{ em um lado apenas } \\
\hline & & & 2 & 2.40 & & 3 & \\
\hline \multirow{2}{*}{4} & \multirow{2}{*}{ Humberto Cosentino } & \multirow{2}{*}{ duplo } & 1 & 2.50 & \multirow{2}{*}{8.00} & 2 & \multirow{2}{*}{ em um lado apenas } \\
\hline & & & 2 & 2.30 & & 0 & \\
\hline \multirow{2}{*}{5} & \multirow{2}{*}{ João José da silva } & \multirow{2}{*}{ duplo } & 1 & 2.50 & \multirow{2}{*}{8.00} & 0 & \multirow{2}{*}{ em um lado apenas } \\
\hline & & & 2 & 2.80 & & 2 & \\
\hline \multirow{3}{*}{6} & \multirow{3}{*}{ Rotatória } & \multirow{3}{*}{ rotatória } & 1 & 2.90 & & 0 & \multirow{3}{*}{ em ambos os lados } \\
\hline & & & 2 & 2.30 & 10.00 & 0 & \\
\hline & & & 3 & 3.00 & & 3 & \\
\hline \multirow{2}{*}{7} & \multirow{2}{*}{ Padre João Manuel } & \multirow{2}{*}{ duplo } & 1 & 2.40 & \multirow{2}{*}{8.00} & 2 & \multirow{2}{*}{ em um lado apenas } \\
\hline & & & 2 & 2.20 & & 0 & \\
\hline 8 & Captano de Camnoc & dunlo & 1 & 2.50 & 790 & 0 & em um lade anenac \\
\hline 8 & Caetano de campos & aupio & 2 & 2.20 & 1.90 & 1 & em um rado apenas \\
\hline 9 & Machado de Acsis & dun & 1 & 2.70 & 790 & 2 & em um lado anenas \\
\hline 9 & IVIacriauo ue ASsis & aupio & 2 & 2.40 & 1.90 & 0 & em um lauo apenas \\
\hline 10 & Riachuelo & duplo & 1 & 2.30 & 780 & 0 & em um lado anenas \\
\hline & & & 2 & 2.10 & 1.00 & 0 & em uni lauo apends \\
\hline MÉDIA & * & * & * & 2.5 & 8.2 & 0.9 & * \\
\hline
\end{tabular}

De acordo com os dados apresentados na Tabela 5, foram elaboradas 4 propostas de modificação do espaço físico das quadras amostradas, visando à melhoria da arborização do bairro. Nesta etapa, levou-se em consideração a (i) limitação da largura do leito carroçável, (ii) localização da fiação e da rede de esgoto, (iii) presença de recuo frontal do 
lote e (iv) necessidade da manutenção de, no mínimo, 1,5 m de largura de calçada, garantindo, desta forma, o trânsito de pedestres (Prefeitura Municipal de São Paulo, 2005). As propostas elaboradas (Figura 9) estão descritas, detalhadamente, a seguir.

\section{Proposta 1}

Esta proposta pode ser aplicada a 6 das 10 quadras amostradas e consiste na redução, por demolição, das calçadas em até 1,5m de largura, garantindo um aumento do leito carroçável e a possibilidade de instalação de um canteiro central ao longo da quadra, contínuo ou segmentado, com 1,20 de largura. Neste caso a quadra se mantém com duplo sentido para o tráfego de veículos, possibilitando ainda que se estacione nas duas faces da rua.

\section{Proposta 2}

Esta proposta contempla as ruas cujo leito carroçável é reduzido, impossibilitando a instalação de um canteiro central, como apresentado na proposta anterior. A alternativa para a melhoria da cobertura vegetal, neste caso, é manter a largura existente das calçadas, propondo alterações em suas estruturas, como a implantação de canteiros de 1,00m de largura nas extremidades e/ou de faixas verdes (grama) no lado oposto. Assim, espera-se obter uma melhoria no sombreamento e aumento da área permeável dessas quadras.

\section{Proposta 3}

A proposta 3 diz respeito a duas situações encontradas durante a visita do grupo às quadras amostradas. Neste caso, foi observada a presença de rotatórias nos cruzamentos de ruas que, dadas as suas dimensões, possibilitam a instalação de um grande canteiro central, com uma árvore de grande porte no centro, circundada por outras de porte inferior. Estas "rotatórias verdes" possibilitariam melhor sombreamento da área, aumento da área permeável e garantiriam melhores condições para a travessia dos pedestres.

\section{Proposta 4}

A última proposta consiste também na redução da largura das calçadas em até $1,5 \mathrm{~m}$ de largura e a instalação de um canteiro central, contínuo ou segmentado, com 1,20m de largura, diferenciando-se da proposta 1 no que diz respeito ao local de estacionamento dos veículos. Aqui, a proposta é que apenas uma face da quadra seja utilizada para estacionamento, mantendo o duplo sentido de circulação. Cabe ressaltar que esta proposta 
foi desenhada em função do pouco tráfego de veículos observado no bairro. Também como melhoria, haverá o aumento do sombreamento (redução de temperatura) e da área permeável da quadra.

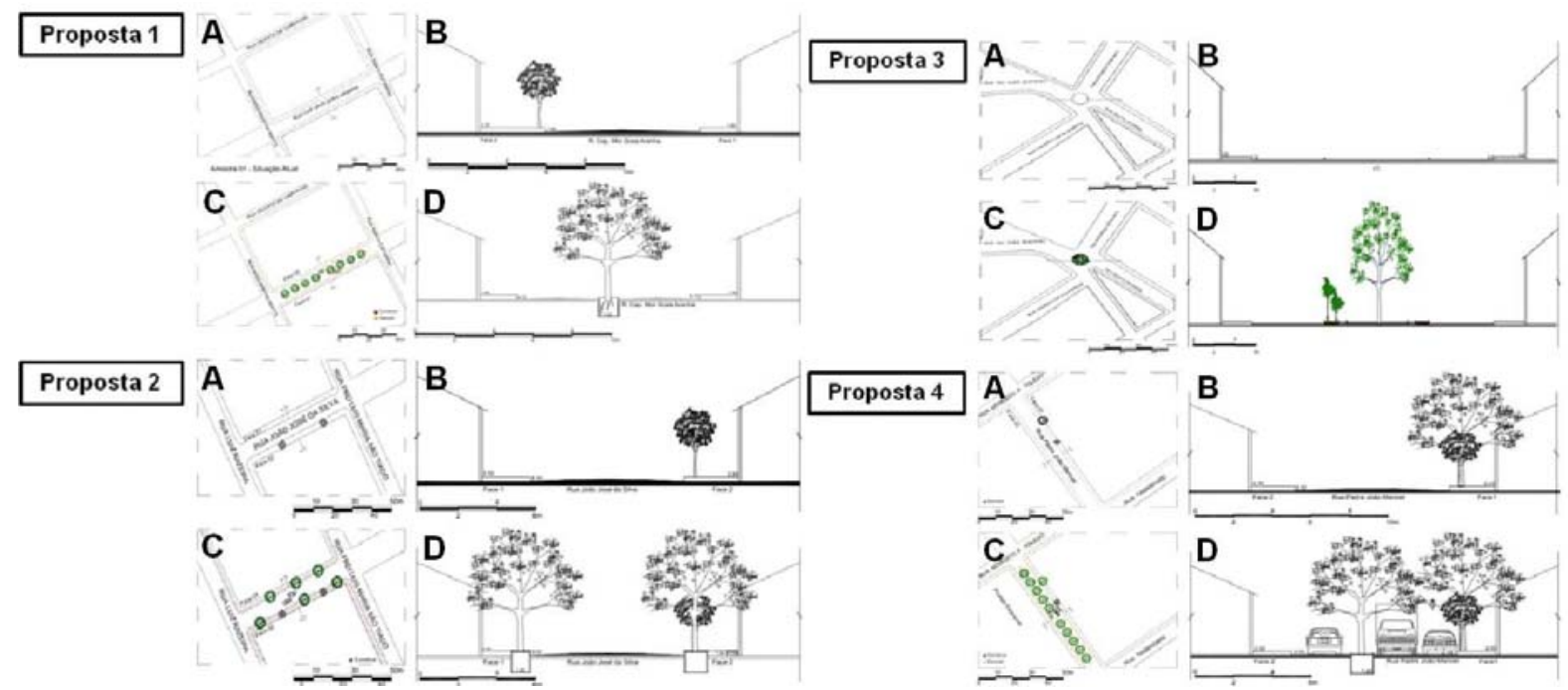

Figura 9. Propostas de desenhos para modificação do espaço físico das ruas amostras do Bairro Nova América. Para cada proposta, são apresentadas a situação atual (A e B) e a situação proposta (C e D).

Analisando as propostas sugeridas e considerando a quantidade adicional de árvores a serem plantadas em cada bairro, é possível perceber que a implantação destas propostas, futuramente, causaria aumento da porcentagem de cobertura arbórea dessas áreas. Com este acréscimo, nota-se que o grau-hora calor é reduzido em até 1,6 vezes. Ou seja, num cenário futuro, aqui idealizado como um dia de verão no horário próximo às 14:00h, nestes bairros, haveria a redução de, aproximadamente, 3 graus Celsius na temperatura que excede a temperatura de neutralidade, passando-se, então, a depender de uma menor quantidade de energia necessária de para o seu resfriamento até tal temperatura. A Tabela 6 apresenta os resultados adquiridos.

Tabela 6. Aumento da porcentagem de cobertura arbórea nos bairros estudados com a aplicação das propostas sugeridas. Nota-se o decréscimo do Grau-hora calor (GHC).

\begin{tabular}{c|ccccc}
\hline Bairro & Área (ha.) & $\begin{array}{c}\text { Cobertura arbórea atual } \\
(\%)\end{array}$ & $G H C\left({ }^{\circ} \mathrm{C}\right)$ & $\begin{array}{c}\text { Cobertura arbórea } \\
\text { prevista (\%)* }\end{array}$ & $\begin{array}{c}\text { GHC } \\
\text { previsto } \\
\left({ }^{\circ} \mathrm{C}\right)\end{array}$ \\
\hline Piracicamirim & 97,6 & 6,95 & 7,75 & 21,24 & 4,59 \\
\hline Jd. Monumento & 55,1 & 7,14 & 7,66 & 22,08 & 4,53 \\
\hline Nova América & 91 & 7,92 & 7,33 & 23,72 & 4,41 \\
\hline
\end{tabular}

* após implantação das propostas. 
O aumento da porcentagem de cobertura arbórea estimada para o bairro Piracicamirim deve-se ao resultado de uma possível implantação de 790 árvores nas vias públicas (calçadas, rotatórias, canteiros centrais e praças), além do enriquecimento das áreas de preservação permanente nas margens do ribeirão Piracicamirim, que, atualmente, se encontra reduzida. Com isso, haveria o aumento de quase três vezes o valor da porcentagem de cobertura arbórea no bairro, passando de 6,78 ha para 20,73 ha de área coberta. No bairro Jardim Monumento, o resultado adquirido baseia-se no acréscimo de 518 árvores com a efetivação das três propostas sugeridas. E, no bairro Nova América, as propostas prevêem a implantação de até 814 árvores, o que promoveria o aumento de 14,4 ha de área de cobertura arbórea.

Os resultados encontrados revelam a dificuldade de implantação de um plano de arborização nas ruas destes bairros. Muitas ruas desprovidas de fiação elétrica acima das calçadas, ainda assim, se tornaram impróprias para receber uma árvore, por haver, abaixo das calçadas, tubulações de redes hidráulicas, ou por haver entrada de carro em frente às propriedades, coincidindo com as dificuldades sugeridas por Soares (1998).

\section{CONCLUSÕES}

Os bairros estudados apresentam condições precárias em termos de arborização, frutos de um ineficiente planejamento urbano. Contudo, apresentam condições de intervenção paisagística e aumento da cobertura arbórea, o que proporcionaria uma melhoria das condições ambientais e, conseqüentemente, do bem estar de sua comunidade.

As intervenções paisagísticas propostas nos bairros acarretariam um incremento da cobertura arbórea nos bairros na ordem de $200 \%$.

As ferramentas e os métodos utilizados propiciaram a superação dos fatores limitantes dos bairros e a construção de alternativas criativas e viáveis para plantios de árvores.

\section{REFERÊNCIAS BIBLIOGRÁFICAS}

AHERN, J. Greenways as strategic landscape planning: theory and application. Dissertação (Mestrado), Wageningen University, Wageningen, Holanda. 2002.

ANSI/ASHRAE. Standard 55 - 2004: Thermal environmental conditions for human occupancy. Atlanta, 26p. 2004.

BARRETO, A.G.O.P; SPAROVEK G.; GIANNOTTI, M. Atlas Rural de Piracicaba. Instituto de Pesquisas Florestais (IPEF). 75p. 2006. 
BRYANT, M.M. Urban landscape conservation and the role of ecological greenways at local and metropolitan scales. Landscape and Urban Planning vol. 76, p. 23-44. 2006.

FRISCHENBRUDER, M.T.M.; PELLEGRINO, P. Using greenways to reclaim nature in Brazilians cities. Landscape and Urban Planning vol. 76, p. 67-78. 2006.

GREY, G.W.; DENEKE, F.J. Urban forestry. New York, John Wiley, 279p. 1978.

ICHINOSE, T.; SHIMODOZONO, K.; HANAKI, K. Impact of anthripogenic heat on urban climate in Tokyo. Atmospheric Environment, Oxford, v.33, n. 24-25, p. 3897-3909, 1999.

INSTITUTO BRASILEIRO DE GEOGRAFIA E ESTATÍSTICA (IBGE). Resultados da Amostra do Censo Demográfico 2007. Disponível em: http://www.ibge.gov.br/home/estatistica/populacao/contagem2007/SP.pdf. Acesso em 12 dez. 2007.

INSTITUTO DE PESQUISA E PLANEJAMENTO DE PIRACICABA (IPPLAP). Banco de Dados. Disponível em http://www.ipplap.com.br/acidade_bdados.php. Acesso em 17 dez. de 2007.

JACQUEMIN, B.; SUNYER, J.; FORSBERG, B.; GÖTSHI, T.; BAYER-OGLESBY, L.; ARCKERMANN-LIEBRICH, U.; MARCO, R.; HEINRICH, J.; JARVIS, D.; TORÉN, K.; KÜNZLI, N. Annoyance due to air pollution in Europe. International Journal of Epidemiology vol. 36, n. 4, p. 809-820. 2007.

JIM, C.Y.; CHEN, S.S. Comprehensive greenspace planning based on landscape ecology principles in compact Nanjing city, China. Landscape and Urban Planning vol. 65, n.3 p. 95-116. 2003.

MARZLUFF, J.M.; EWING, K. Restoration of fragmented landscapes for the conservation of birds: a general framework and specific recommendations for urbanizing landscapes. Restoration Ecology, vol 9, n.3, p. 280-292. 2001.

MOLL, G. Anatony of Urban Forest. American Forest. vol. 94, n. 7/8, p. 22-24/74-75. 1988. MONTEIRO, C. A. DE F.; MENDONÇA, F. (Org.). Clima Urbano. São Paulo: Editora Contexto, 192p. 2003.

MORE, T. A.; STEVENS, T.; ALLEN, G. Valluation of urban parks. Landscape and Urban Planning vol. 15, p. 139-152. 1988.

NILON, C.H.; BERKOWITZ, A.R.; HOLLWEG, K.S. Editorial: Understanding urban ecosystems: A new frontier for science and education. Urban Ecosystems, New York, vol. 3, n.3-4, p. 3-4. 1999.

PAIVA, H.N. de; GONÇALVES, W. Florestas urbanas: planejamento para melhoria da qualidade de vida. Viçosa: Aprenda Fácil, 177p. (Série Arborização Urbana, 2). 2002.

PENG, C.; WU, X.; LIU, G.; JOHNSON, T.; SHAH, J.; GUTTIKUNDA, S. Urban Air Quality and Health in China. Urban Studies vol. 39, n.12, p. 2283-2299. 2002. 
SÃO PAULO (MUNICÍPIO). Guia para a mobilidade acessível em vias públicas. Comissão Permanente de Acessibilidade (CPA), Secretaria de Habitação (SEHAB), 77p. 2005.

REES, W.E. Urban ecosystems: The human dimension. Urban Ecosystems. New York, vol.1, n. 1, p.63-75. 1997.

ROLLO, F.M.A.; SILVA FILHO D.F; COUTO H.T.Z.; POLIZEL J.L. Uso de cenas videográficas para a avaliação da floresta urbana. Revista da Sociedade Brasileira de Arborização Urbana. vol.2, n. 3, p. 63-79. 2007.

ROLLO, F.M.A.; SILVA FILHO D.F; COUTO H.T.Z.; POLIZEL J.L; MIZUTA D.; PASSARINI, L.; GARCIA, R. G. S; MOLIN, P. G.; CEZARETTI, E. S.; SARTORI, A. G. O.; ALMEIDA, A. M. Avaliação do tecido urbano de Piracicaba- SP em dois momentos por meio de imagens aéreas multiespectrais de alta resolução. In: XIII Simpósio Brasileiro de Sensoriamento Remoto, Florianópolis, 2007. Anais..., Florianópolis, Brasil, INPE, 2007, p. 653-660. 2007b.

RORIZ, M. Consumo de energia no condicionamento térmico de edificações: um método de avaliação. In: Encontro Latino-Americano Sobre Conforto no Ambiente Construído, 3., 2001, São Paulo. Anais...São Carlos: 2001.

SHASUA-BAR, L.; HOFFMAN, M. E. Geometry and orientation aspects in passive cooling of canyon streets with trees. Energy and Buildings, v. 35, p. 61-68, 2003.

SILVA, R. S.; MAGALHÃES, H. Ecotécnicas urbanas. Ciência \& Ambiente. n.7, p. 33-42. 1993.

SMITH, J. B.; BHATTI N.; MENZHULIN, G.; BENIOFF, R.; BUDYKO M.I.; CAMPOS, M.; JALLOW, B., RIJSBERMAN, F. Adapting to Climate Change. Assessments and Issues. New York: Springer. 475p. 1996.

SOARES, M.P. Verdes urbanos e rurais: orientação para arborização de cidades e sítios campesinos. Porto Alegre: Cinco Continentes, 242p. 1998.

TIMÁR, J. The main features of suburbanization in the Great Hungarian Plain. Landscape and Urban Planning vol. 22, p. 177-187. 1992.

VASCONCELOS, P.C; BALASUBRAMANIAN, R; BRUNS, R E; SANCHES-CCOYLLO, O.; Andrade, M. F.; Flues, M. Water-Soluble Ions and Trace Metals in Airborne Particles Over Urban Areas of the State of São Paulo, Brazil: Influences of Local Sources and Long Range Transport. Water Air and Soil Pollution vol. 186 n. 1 - 4, p. 63-73. 2007.

VELASCO, G.D.N. Potencial da arborização viária na redução do consumo de energia elétrica: definição de três áreas na cidade de São Paulo-SP, aplicação de questionários, levantamento de fatores ambientais e estimativa de Graus - Hora de calor. 123p. Tese (Doutorado em Agronomia) Escola Superior de Agricultura "Luiz de Queiroz", Piracicaba, 2007. 
VITOUSEK, P.M.; MOONEY, H.A.; LUBCHENCO, J.; MELILLO, J.M. Human domination of Earth's ecosystems. Science vol. 277, n. 5325, p. 494-499.1997.

WACKERNAGEL, M.; REES, W. Our Ecological Footprint: Reducing Human Impact n the Earth. The New Catalyst Bioregional, Philadelphia, PA: New Society Publishers,160p. 1996. 